\title{
ENFERMAGEM, ESTA DESCONHECIDA *
}

** Ana Shirley Valverde Meirelles

** Ethevalda Neves de Carvalho

$\mathrm{RBEn} / 15$

MEIRELES, A.S.V., CARVALHO, E.N. - Enfermagem, esta desconhecida. Rev. Bras. Enf.; DF, $30: 185-201,1977$.

\section{INTRODUÇÃO}

Embora muitos autores se empenhem em definir e divulgar a Enfermagem como profissão moderna e de nível superior, seu trabalho só tem conseguido ecoar entre os que já militam nessa profissão e nas suas correlatas. A população em geral, ainda não se apercebe verdadeiramente das razōes que levaram as autoridade governamentais a elevar a Enfermagem à condição de nível superior. Em editorial recente, um periódico de grande tiragem parece ratiflicar a opinião pública nesse sentido (9).

Dessa forma, a Enfermagem continua desconhecila para o público brasileiro em geral, e, o que é pior, para os jovens do nosso país. Exemplos denodados, de enfermeiras, não conseguem ultrapassar as fronteiras da área de saúde, enquanto imagens negativas estereotipadas pela literatura são frequentemente reproduzidas e divulgadas pelos nossos efetivos meios de comunicação. A figura de Sarey Gamp, pintada por Charles Dickens, para ironizar as condiçōes de enfermagem da época, vive de tal maneira na mente de todos, que é invocada com freqüência (6). Com mais freqüência até do que a de Edith Cawell, não obstante sua atuação na 1. a Guerra Mundial ter sido consagrada em bronze, para a memória de seus compatriotas (2 e 10). Assim, fica difícil para os jovens e suas famílias aceitarem e optarem por essa profissão, e fácil para nós, enfermeiras e aceitação de suas atitudes frente à Enfermagem que, desde 1860 , pela atuação e alto senso de discernimento de Florence Nightingale, já goza das prerrogativas de uma profissão moderna.

$O$ vestibular unificado e a dilatação do número de vagas, nas Escolas de Enfermagem do Rio de Janeiro, determinaram uma maior afluência de estudantes para essa área das Ciências da Saúde. Porém, o contato com alunos recém-chegados às Escolas de Enfermagem revela que a

- Tema livre - XXVIII CBEn, RJ, 1976.

* Auxiliares de ensino da Escola de Enfermagem da UFRJ. 
MEIRELES, A.S.V., CARVALHO, E.N. - Enfermagem, esta desconhecida. Rev. Bras. Enf.; DF, 30 : 185-201, 1977.

maioria deles desconhece o significado real da profissão. Isso nos parece uma variável interveniente em seu ajustamento, que poderia ter seus efeitos minorados, mediante uma maior e melhor divulgação da Enfermagem Moderna como profissão. Revelação análoga resulta de contatos formais e informais realizados com alunos de $1 .^{\circ}$ e $2 .^{\circ}$ graus, de nossa cidade, mesmo aqueles que posteriormente se candidatam às Escolas de Enfermagem. No entanto, as excessões confirmam a regra geral.

\section{- OBJETIVOS E HIPOTESE}

O presente trabalho encerra seus obJetivos em 2 itens:

a) pesquisar o nível de sensibilização de alunos do $2 .^{\circ}$ grau pela Enfermagem;

b) esclarecer a "atitude comportamental" de alunos oriundos do ciclo básico diante do ensino de enfermagem propriamente dito, em seus estágios iniciais.

No intuito de alcançar esses objetivos, formulamos a seguinte hipótese:

- os estudantes do $2 .^{\circ}$ grau da cidade do Rio de Janeiro estão mal informados sobre a profissão de Enfermagem.

Com a finalidade de melhor esclarecer os objetivos acima propostos, consideramos oportuno explicar com mais detalhes o significado real que lhes atribuímos. Assim é que:

a) quando nos referimos à sensibilização dos alunos do $2 .^{\circ}$ grau, pretendemos pesquisar o que eles conhecem e percebem sobre as atribuiçōes, responsabilidades e satisfações inerentes à Enfermagem como profissão moderna;

b) no item referente à atitude comportamental dos alunos oriundos do ciclo básico, pretendemos estabelecer uma correlação entre a atitude negativista e insatisfeita desses alunos, ante a aceitação de certas normas, princípios e procedimentos que a profissão impõe, e as escolas de enfermagem desde o início procuram incutir - e o conteúdo de informaçōes que eles trazem consigo sobre a Enfermagem. Embora não tivessemos estendido esta pesquisa a alunos já ingressos no Ciclo Básico, consideramos que, por extensão e pela experiência vivida cotidianamente com esse tipo de aluno, alguns esclarecimentos pudessem, certamente, adoir. Isso, levando em consideração que a grande maioria que ingressa anualmente no Ciclo Profissional, confessa pouco, ou nada saber definidamente sobre a Enfermagem como profissão de nível superior.

\section{METODOLOGIA}

População estudada: alunos da 3.8 série do $2 .^{\circ}$ grau de oito escolas desta cidade, assim distribuídas: duas da zona sul, duas da zona centro, duas da zona norte e duas da zona rural. Das oito escolas, $50 \%$ pertencem à rede privada e $50 \%$ à rede estadual de ensino. A distribuição obedeceu a esse critério por acreditarmos abranger todas as zonas geo-sócio-econômicas da cidade. A escolha, das escolas em si, foi aleatória.

Coleta de dados: feita pelas autoras através de aplicação de questionário com 12 itens. (Anexo 2). A diretora da Escola de Enfermagem da UFRJ dirigiu Ofício aos diretores das escolas sorteadas, (Anexo 1) os quais foram entregues pessoalmente, ocasião em que eram agendados as datas para aplicação dos questionários e explicados os objetivos e finalidades do trabalho.

$\mathrm{Na}$ oportunidade da aplicação dos questionários as autoras foram recebidas pelos coordenadores de curso das escolas sorteadas, que as introduziram nas classes destinadas à pesquisa. Ao se apresentarem aos alunos, as autoras omitiam sua condição de enfermeiras identificando-se apenas como professoras da UFRJ. Esse comportamento foi adotado visando não influenciar a opinião dos respondentes. 
MEIRELES, A.S.V., CARVALHO, E.N. - Enfermagem, esta desconhecida. Rev. Bras. Enf.; DF, 30 : 185-201, 1977.

A receptividade por parte dos alunos foi muito boa, não havendo recusas em responder ao questionário. O tempo médio para aplicação foi de 20 minutos.

\section{ANALISE DOS DADOS}

A população estudada compunha-se de 213 alunos, dos quais 64\% (136 alunos) eram do sexo masculino e $36 \%$ (77 alunos) do sexo feminino, como mostram a Tabela I e o Gráfico I.

A faixa etária dos alunos era de 16 a 30 anos, sendo a média de idade 20 anos, com um desvio padrão de 2,5 anos, o que significa dizer que aproximadamente $68,3 \%$ dos alunos estavam na faixa de 17,5 a 22,5 anos de idade. Tabela II e Gráfico II.

Na Tabela III e Gráfico 3 pode-se observar a distribuição numérica e percentual dos alunos, segundo a profissão que pretendiam seguir. A maior preferência incidiu sobre Engenharia em seus diversos ramos, com 15,5\% (33 alunos); em segundo lugar de preferência vem $\mathrm{Me}$ dicina, com 14,1\% (30 alunos); 10,8\% (23 alunos) ainda não se decidiram sobre a profissão a seguir; a Enfermagem aparece em 10.0 lugar de preferência com $3.8 \%$ dos pesquisados (7 alunos); com a finalidade de simplificar a tabulação dos dados, incluiu-se na categoria de "Outras", as profissões que não conseguiram alcançar mais de $1 \%$ na preferência dos alunos. Dessa forma ficaram ai incluídas cerca de 20 profissōes diversas, que representam 12,5\% (27 alunos) dos pesquisados.

A Tabela IV mostra a opinião dos alunos sobre permanência e influência na escolha da profissão. Dos 213 alunos, $66,7 \%$ afirmaram que não mudariam de escolha se não conseguissem passar no vestibular, $31,5 \%$ mudariam e $1,8 \%$ não responderam a esse item.

Quanto ao item sobre a influência na escolha da profissão, a grande maioria dos alunos apontou a "decisão própria" como mais influenciadora e em segundo lugar apareceu a "orientação vocacional". Em virtude de ser permitido aos alunos assinalarem mais de uma alternativa em cada item, o total de alunos excede a 213 e o percentual foi calculado para cada alternativa de "per si".

A Tabela $\mathrm{V}$ e o gráfico 4 mostram o grau de utilidade atribuído pelos alunos a 10 profissões constantes de uma lista que lhes foi apresentada. Na opinião dos alunos, a profissão mais útil à sociedade é a Medicina, com grau 9,5, seguida pela Enfermagem com grau 6,6; como profissão menos útil à sociedade ficou a $\mathrm{Ar}$ quitetura, com 3,5.

A escolha das 10 profissōes constantes da lista, efetuou-se por sorteio dentre 24 profissōes divulgadas pelo Cesgranrio, com relação candidato-vaga superior a quatro. (11)

Na Tabela VI pode-se observar a opinião dos alunos sobre caracterização, conhecimento e posicionamento da Enfermagem em nivel superior. $74 \%$ das respostas caracterizam a Enfermagem como profissão em evolução, $18,2 \%$ como profissão feminina, e as demais opiniōes não apresentam expressividade numérica.

No item que se refere à Enfermagem como suficientemente conhecida, $49,3 \%$ dos alunos consideram só em parte; $408 \%$ consideram não conhecida e $9,9 \%$ consideram suficientemente conhecida.

Questionados sobre, se já haviam assistido a alguma divulgação da enfermagem, $28,6 \%$ responderam que sim, e $\mathbf{7 1 , 4 \%}$ responderam que não.

Do total de alunos pesquisados $\mathbf{7 5 , 1 \%}$ acharam que a Enfermagem devia ser uma profissão de nivel superior, enquanto $23,9 \%$ acharam que não, e $1 \%$ não respondeu à pergunta.

A Tabela VII mostra os motivos para abraçar a profissão, as funçōes essenciais e os requisitos mais necessários ao enfermeiro, na opinião dos alunos. Esses, na maioria, $66,2 \%$, consideraram que 
MEIRELES, A.S.V., CARVALHO, E.N. - Enfermagem, esta desconhecida. Rev. Bras. Enf.; DF, $30: 185-201,1977$.

quando um jovem abraça a carreira de enfermagem ele vê oportunidade para ajudar outras pessoas; $34,3 \%$ consideraram que a oportunidade para atuar em profissão carente de mão de obra é um dos motivos significativos; os outros dois motivos apresentados ocuparam lugar de pouca relevância, embora $8,9 \%$ do total de alunos considerassem que o motivo fosse pouco preparo para concorrer a outra profissão.

No item referente a funções essenciais do enfermeiro, a maioria das opiniōes $(65,7 \%)$ recaíram "cuidar de pessoas doentes"; $59,2 \%$ referiu-se a "orientar a população no cuidado da saúde"; "participar dos programas de saúde do país"; obteve $54,5 \%$ das opiniōes; "aplicar injeçōes e outros medicamentos", $44,1 \%$ (quase metade das opiniōes); "fazer pesquisas na área da saúde, $41,8 \%$, e chefiar serviços de enfermagem, apenas $17,4 \%$ (menos de $1 / 6$ da população pesquisada).

Entre os requisitos mais necessários a um enfermeiro, o referente a dedicação e consideração ao ser humano atingiu $93,9 \%$ das opiniōes, secundado, de longe, por "conhecimentos científicos", com $43,3 \%$; "cultura geral" está representada por $21,6 \%$ e "boa aparência", em último lugar, com $9,8 \%$.

Nos itens dessa tabela, houve permissão para os respondentes assinalarem mais de uma alternativa. Dessa forma os totais numéricos e percentuais excederam os limites convencionais.

\section{- INTERPRETAÇAO DOS DADOS}

No sentido de conferir a esse trabalho um grau de simplicidade, esta parte será feita concomitantemente com a Revisão da Literatura que como é óbvio, não poderia faltar.

A bibliografia consultada não revelou nenhum trabalho de idêntica natureza à desse. Porém, outros aspectos análogos já merecem estudo de alguns autores (1 e 5).

A idade média de 20 anos nos revela uma população jovem, como era de se esperar para estudantes desse nível de escolaridade. A pretensão profissional dos estudantes mostra uma grande variedade de escolha, deferindo do que se observava até poucos anos atrás, quando havia uma concentração maciça sobre aquelas profissōes consideradas tradicionais. $O$ aparecimento de novas profissōes de nível universitário conseguiu despertar 0 interesse dos jovens para outras áreas de ação, livrando-os do "fantasma dos excedentes" e permitindo-lhes aplicar mais cedo suas potencialidades para o desenvolvimento do país. Porém o percentual de pretendentes à Enfermagem (apenas 3,3\%) nos leva a raciocinar em dois sentidos: $10^{\circ}$ - não está condizente com a necessidade de enfermeiros em nosso país nem com a relação candidatovaga observada no último vestibular unificado (11). $2 .^{\circ}$ - embora seja uma profissão nova, não o é tanto assim pois desde 1949, a lei 775 determinou sua inclusão em nível superior. Parece sugerir uma permanência de estereótipos do passado ( ) e uma falta de divulgação da profissão entre os alunos do $2^{\circ}$ grau. Outras profissōes mais novas já conseguem carrear mais significativo número de pretendentes como é o caso da Psicologia, Administração ou Comunicação. Além do mais, boa percentagem dos alunos ainda não se decidiu vocacionalmente, o que nos enseja uma oportunidade para agir no despertar de interesse entre esses jovens.

Esse pensamento consegue ratificação quando observamos que apenas $9,9 \%$ dos alunos pesquisados afirmaram ser a Enfermagem uma profissão suficientemente conhecida entre os alunos do $2 .^{\circ}$ grau e $\mathbf{7 1 , 4 \%}$ deles dizerem nunca terem assistido a nenhuma divulgação da profissão, quer através de leituras, filmes, confe- 
MIIRELES, A.S.V., CARVALHO, E.N. - Enfermagem, esta desconhecida. Bev. Bras. Enf.; DF, 30 : 185-201, 1977.

rências, palestras ou outro qualquer meio.

Numa prévia feita para esse trabalho, questionamos 42 professoras das três Escolas de Enfermagem que mantêm curso de graduação na cidade do Río de Janeiro, sobre a divulgação da Enfermagem nas escolas do $2 .^{\circ}$ grau. A maioria delas $78,6 \%$ considerou que a enfermagem não está bem divulgada e confessou que em seu contato inicial com estudantes de enfermagem, eles não percebem verdadeiramente as atribuiçōes, as responsabilidades e as satisfaçōes de ser enfermeiro, ou o fazem apenas em parte. Por premência de espaço, os questionários relativos a essa prévia não foram apresentados no presente trabalho, bem como o resultado dos cados obtidos. No entanto, as autoras se pōem à disposição dos interessados.

A posição assumida pelos alunos é mostrada na tabela III, revela uma radícalização própria da faixa etária, na sua constante necessidade de auto-afirmação. Mais da metade não mudaria de escolha da profissão, e dos que mudariam de escolha apenas $9,4 \%$ dizem fazê-lo após a primeira tentativa. Considere-se, porém, que o grupo ainda nāo se submeteu ao vestibular, cujo insucesso é considerado o grande influenciador de mudanças.

Nessa mesma linha de pensamento está a afirmação que fazem no que se refere à influência na escolha da profissão, onde $89,2 \%$ invocam a decisão própria como fator preponderante.

E interessante notar que na ordenação de profissōes os alunos ocuparam as seis primeiras posiçōes com profissōes de Servir (Tabelas V e Gráfico 4).

O grau máximo de utilidade, atribuído à Medicina atesta a influência das profissōes tradicionais na sociedade. $O$ 2.0 lugar, atribuído à enfermagem, já é alentador, pois apesar de não a terem escolhido, consideram-na de real utili- dade. Coerentemente não arrolaram como mais úteis, outras profissōes de grande prestígio social.

Ao interpretar a caracterizaçāo da Enfermagem cabe considerá-la como uma profissão tradicionalmente feminina, segundo constatação feita por Monteiro de Castro e outros, no antigo Estado da Guanabara. Outra demonstraçāo dessa característica é a predominância de elementos do sexo feminino graduados em Enfermagem. Em 1961 a percentagem era de $97 \%$ contra $3 \%$ do elemento masculino. Mais recentemente a cifra se apresenta pouco modificada, sem alterar a predominância.

Na cidade do Río de Janeiro, só a partír do advento do vestibular unificado em 1971 é que todas as Escolas de Enfermagem começavam a receber elementos do sexo masculino em seu corpo discente, o que até então só ocorria em uma escola desta cidade.

Esse tipo de caracterização parece estar diminuindo entre os jovens, pois apenas $19,7 \%$ dos pesquisados a indicaram, enquanto a grande maioria caracterizou a profissão como em evolução $(80,3 \%)$, o que corresponde aos esforços e interesses dos enfermeiros e suas associaçōes de classe.

O posicionamento da Enfermagem em nível superior parece não ter atingido nem satisfeito à população em geral ( ), apesar da disposição legal nesse sentido, da recente criação dos Conselhos de Enfermagem e da efetiva atuação de alglins enfermeiros nos setores de saúde do país. A indicação de que a Enfermagem não deve ser uma profissão de nível superior, por $23,9 \%$ dos alunos pesquisados, indica uma falta de conhecimento das funçōes do enfermeiro e mais uma vez a necessidade da divulgação da profissão.

A elaboração de uma teoria sinergística da enfermagem (23), visando esclarecer o que é enfermagem e quais as suas funçōes, indica algumas açōes diretas da 
MEIRELES, A.S.V., CARVALHO, E.N. - Enfermagem, esta desconhecida. Rev. Bras. Enf.; DF, 30 : 185-201, 1977.

enfermeira para com seus pacientes. Elas podem ser resumidas e entendidas como preservação, prevenção e restabelecimento da saúde, atuando sinergisticamente, e adicionadas de implementação da terapêutica e da atividade diagnóstica do médico. A autora salienta que embora essa última seja muitas vezes super-valorizada, não é a única nem a mais importante das açōes da enfermeira: é mais uma delas.

Alguns mitos sobre a profissão de Enfermagem (8) podem influenciar negativamente o seu desenvolvimento, se tomados separadamente para identificar a função da enfermeira. Aqui também, a autora mostra a complexidade das funçōes da enfermeira e a necessidade da conciliação de várias atividades: ser humanamente caridosa, ajudar ao médico ou a outros profissionais da equipe, prevenir a doença, promover a saúde, cuidar de doentes, executar bem os procedimentos técnicos e administrar serviços de enfermagem, sem no entanto arraizar-se exclusivamente a um deles.

No capítulo 1 do Tratado de Enfermeria Prática (7) a autora discorre sobre a multiplicidade de açōes da enfermeira. Indica como funçōes da enfermeira: cuidar do paciente e interessar-se por ele, ajudar o médico no plano terapêutico, aconselhar em assuntos de saúde, coordenar a equipe de saúde, administrar a equipe de enfermagem.

Nesta pesquisa a maior ênfase dada pelos alunos pesquisados foi para a função "cuidar de pessoas doentes" que sugere a permanência de um dos mitos da enfermagem (8) ou o desejo do público em geral de ver os doentes cuidados realmente por enfermeiros. As funçōes relativas a prevenção de doença e promoção da saúde tiveram escolhas semelhantes, com mais da metade dos alunos; o item menos valorizado foi "chefiar serviços de enfermagem", que é sabidamente função essencial do enfermeiro; e não pode nem deve ser delegada a outro profisional; "aplicar inje- cões e outros medicamentos" foi função significativamente assinalada, embora possa ser delegada a outros membros da equipe de enfermagem.

Entre os requisitos mais necessários a um enfermeiro uma percentagem altamente significativa $(93,9 \%)$ escolheu "dedicação e consideração ao ser humano". Esse fato coincide com o pensamento dos enfermeiros em geral que apesar de aprimorar seus conhecimentos técnico-científico valorizam sempre os aspectos de humanização. “... A preservação dos princípios cristãos de amor e dedicação aos que sofrem, simpatia para com os infelizes e de tolerância para com todos, sãos e doentes, deve constituir um dos objetivos de qualquer programa de enfermagem..." (3). Ao lado desta afirmação a autora ainda exalta, para as enfermeiras, qualidades que podem ser referidas à aparência pessoal. Assim ela fala de qualidades que tornam mulheres mais femininas e mais humanas: sensibilidade, cordialidade elegância no falar e no vestir, etc. A tabela VII mostra que a "boa aparência pessoal' contribui com percentagem de baixa expressividade para os requisitos necessários a um enfermeiro. Houve marcante irregularidade na opinião dos alunos sobre os requisitos apresentados, quando, na verdade, eles representam parcelas mais ou menos equivalentes para a profíssão. A colocação de "conhecimentos cientificos" $43 \%$ ) e "cultura geral" $(21,6 \%)$ demonstra mais uma vez a falta de informação dos alunos sobre a Enfermagem como profissão de nivel superior.

\section{- CONCLUSÓES}

A Enfermagem como profissão moderna e como campo aberto aos jovens, é ainda pouco divulgada.

Os alunos do $2 .^{\circ}$ grau estão mal informados sobre a inclusão da Enfermagem em nível universitário, e parte considerável ainda questiona essa colocação. 
MEIRELES, A.S.V., CARVALHO, E.N. - Enfermagem, esta desconhecida. Rev. Bras.

Enf.; DF, 30 : 185-201, 1977.

A pouca divulgação os leva a atribuir à Enfermagem funções não essenciais.

Não obstante confessarem que nunca assistiram a programas de divulgação, colocam a profissão em segundo lugar de utilidade na sociedade.

Atribuindo percentuais tão altos a requisitos que envolvem princípios cristãos e humanitários, revelam uma tendência à preservação de valores tradicionais que devem assim permear as modernas linhas de enfoque no ensino e no exercício da profissão. No entanto, subestimam, a necessidade dos conhecimentos científicos.

\section{REFERENCIAS BIBLIOGRAFICAS}

1. AlCANTARA, G. de - A enfermagem como categoria profissional: obstáculos à sua expansão na sociedade brasileira "(Tese de concurso à cátedra de história de Enfermagem e ética) Ribeirão Preto, 1966.

2. BASTOS, REYNALDO - A Enfermeira Edith Cavel. Ed. Mandarino. Rio de Janeiro (s.d.).

3. BRODT, DAGMAR, E. - A Synergistic Theory of Nursing. Am. Journal of Nursing (8) 1974-1976. August, 1969.

4. Carvalho, A C. - A docente de enfermagem como modelo a ser imitado. Revista Grasileira de Enfermagem (6) 527-531, 1973.

5. CaStro, I. B. e col. - Modificaçōes da imagem da enfermeira percebida pelos estudantes durante 0 curso de graduação de enfermagem.
Rev. Brasileira de Enfermagem (2) : 180-192, 1974.

6. DICKENS, C. - Martin Chuzzlewit. Collins Clear Type Press. London and Glasgorv (s.d.).

7. DUGAS, B. W. - Tratado en Enfermeria Prática. Ed. Interamericana, México, 1972.

8. HORTA, W. A. - Os mitos da enfermagem. Rev. Enfermagem em Novas Dimensōes 1 (2): 60-63 - S. Paulo, 1975.

9. JORNAL DO BRASIL - Falhas Estruturais. Rio de Janeiro 16.5.76.

10. MUIRHEAT, L. RUSSEL - Short Guide to London Ernest Benn Limited. London, 1947.

11. O GLOBO - Vestibular Unificado Termina Hoje. Rio de Janeiro 18.01.76. 
MEIRELES, A.S.V., CARVALHO, E.N. - Enfermagem, esta desconhecida. Rev. Bras. Ene.; DF, 30 : 185-201, 1977.

TABELA I - Distribulção numérica e percentual, dos alunos, por sexo

\begin{tabular}{l|c|c}
\hline \multicolumn{1}{c|}{ SEXO } & NQ DE & ALUNOS \\
\hline Feminino & 136 & 64 \\
Masculino & 77 & 36 \\
\hline TOTAI & 213 & 100 \\
\hline
\end{tabular}

IABBLA II - Cálculo da média e desvio padrão das idades dos alunos

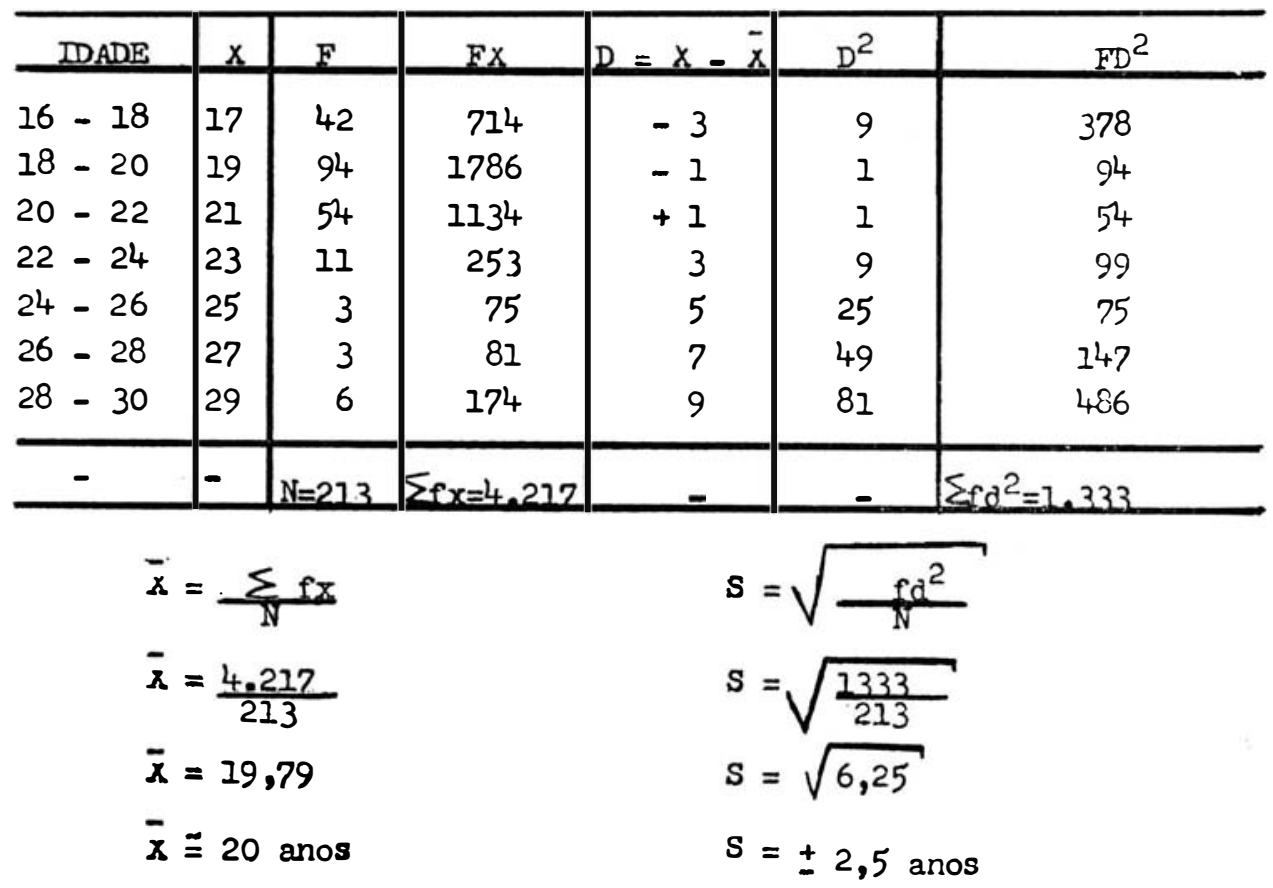


MaIRELES, A.S.V., CARVALHO, E.N. - Enfermagem, esta desconhecida. Rev. Bras. Ene.; DF, 30 : 185-201, 1977.

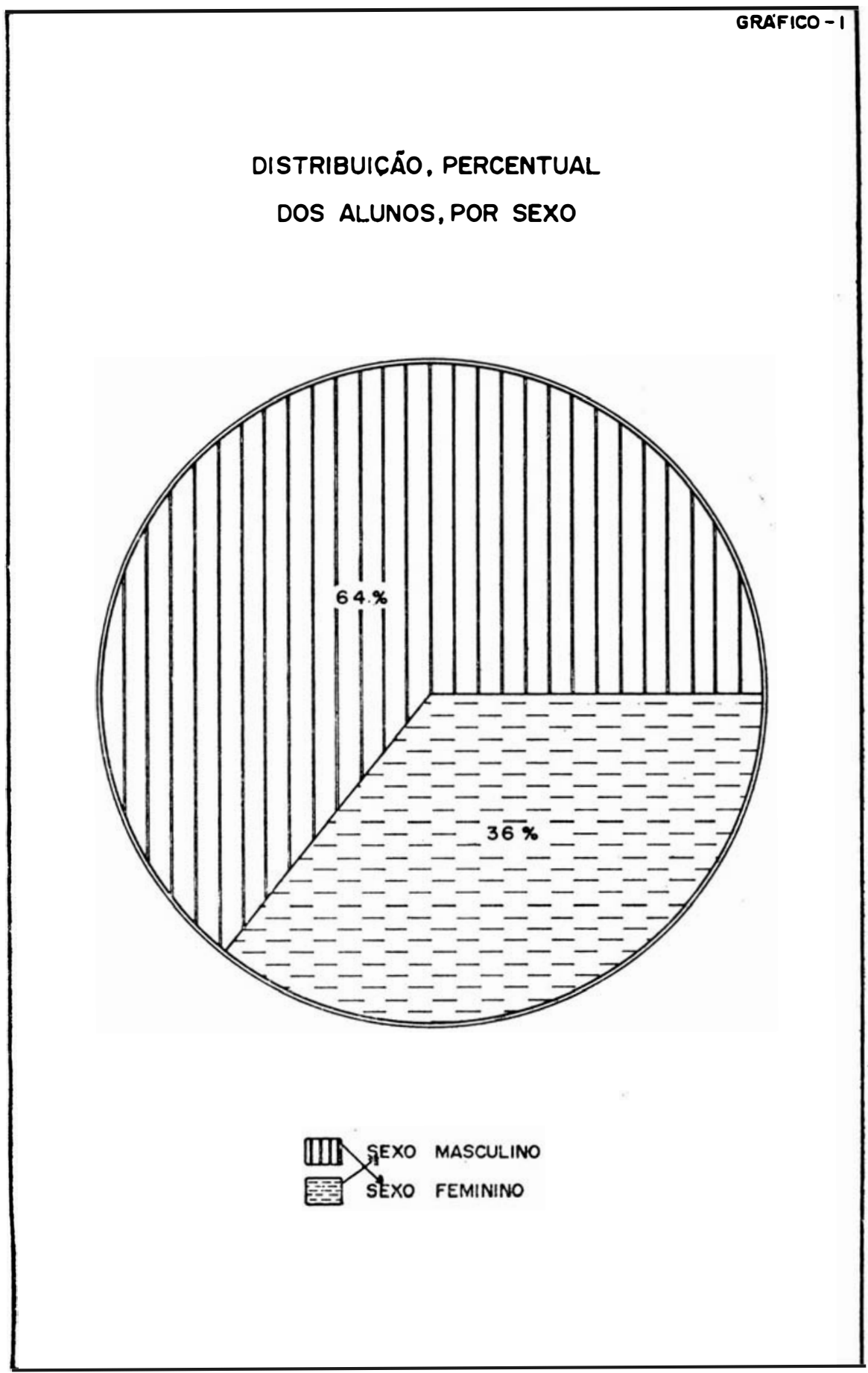


MEIRELES, A.S.V., CARVALHO, E.N. - Enfermagem, esta desconhecida. Rev. Bras. Enf.; DF, $30: 185-201,1977$.

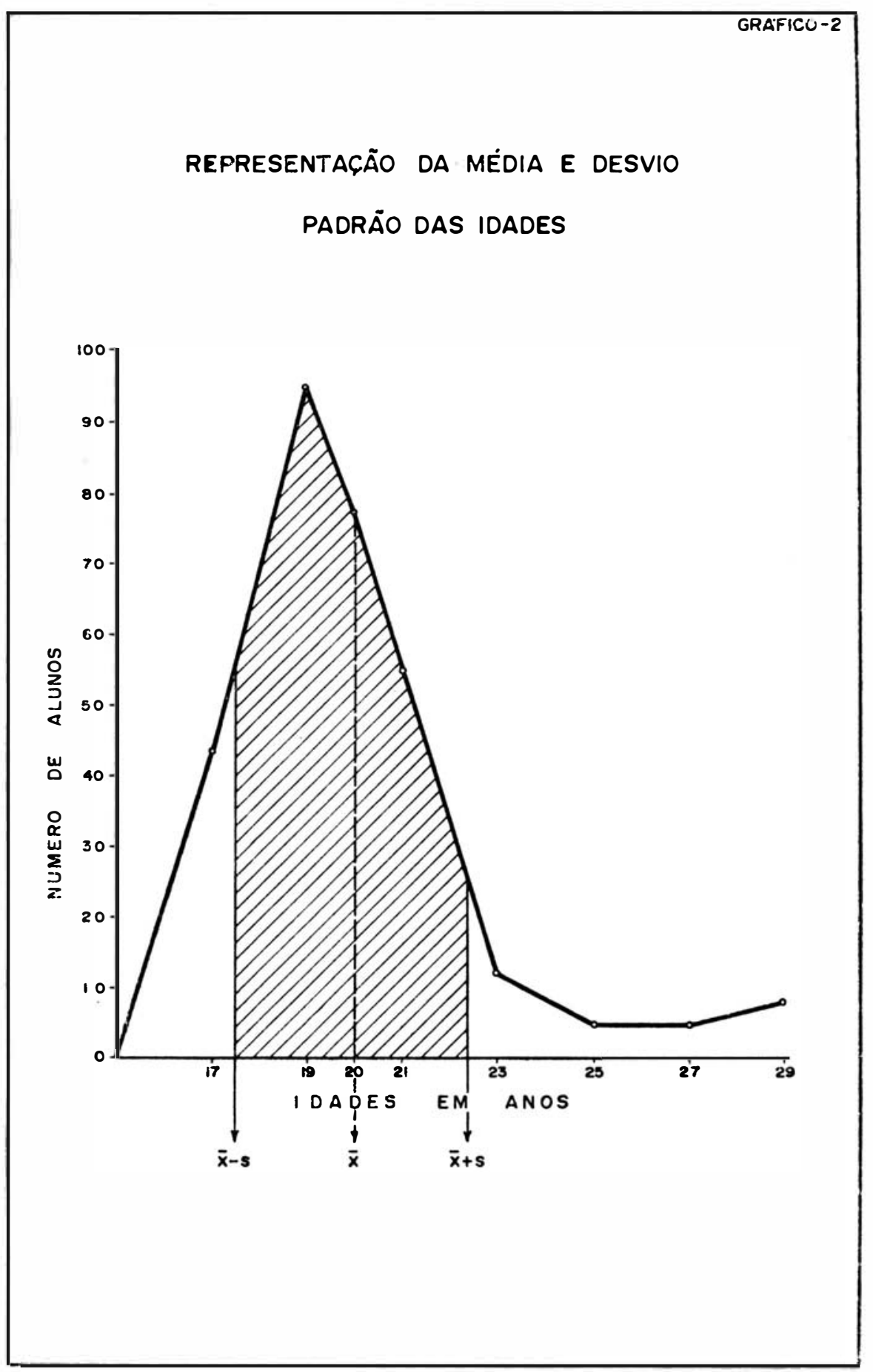


MEIRELES, A.S.V., CARVALHO, E.N. - Enfermagem, esta desconhecida. Rev. Bras. Enf.; DF, 30 : 185-201, 1977.

TABELA IIT - Distribulção numérica e percentlial dos alunos, segundo a profissão pretendida

\begin{tabular}{|c|c|c|}
\hline PROFISSOES & $\begin{array}{l}\text { NO } \\
\text { DE } \\
\text { ALUNOS }\end{array}$ & $\therefore$ \\
\hline Engenharia & 33 & 15,5 \\
\hline Medicina & 30 & 14,1 \\
\hline Não decld1u & 23 & 10,8 \\
\hline Psicolōgla & 19 & 8,9 \\
\hline Magistério & 14 & 6,6 \\
\hline Administração & 13 & 6,1 \\
\hline Comunicação & 11 & 5,2 \\
\hline Serviço Soclal & 8 & 3,8 \\
\hline Educação F1sıca & 8 & 3,8 \\
\hline Enfermagem & 7 & 3,3 \\
\hline Odontologla & 6 & 2,8 \\
\hline Arquitetura & 4 & 1,9 \\
\hline Advocacia & 4 & 1,9 \\
\hline Economia & 3 & 1.4 \\
\hline Veterinária & 3 & 1,4 \\
\hline Outras & 27 & 12,5 \\
\hline TOTAL & 213 & 100.2 \\
\hline
\end{tabular}


MEIRELES, A.S.V., CARVALHO, E.N. - Enfermagem, esta desconhecida. Rev. Bras. Enf.; DF, $30: 185-201,1977$.

DISTRIBUICÅO PERCENTUAL DOS ALUNOS. SEGUNDO A PROFISSÃO PRETENDIDA

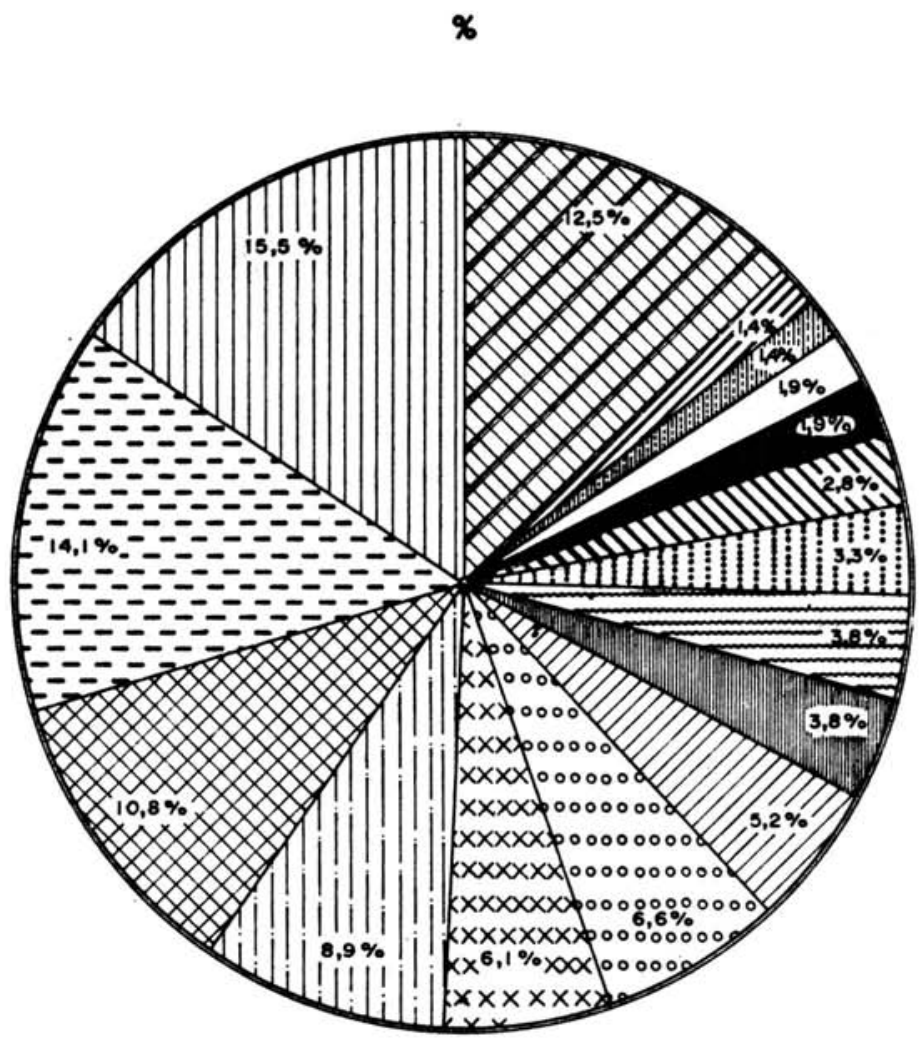

IIII ENGENHARIA

E-T MEDICINA

NAO DECIDIU

PSICOLOGIA

ख్X ADMINISTRACÅO

::: MAGISTÉRIO

UlA COMUNICACÅO

II SERVICO SOCIAL
EDUCACÁO FISICA

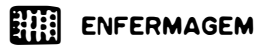

AV ODONTOLOGIA

ARQUITETURA

ADVOCACIA

明脚 ECONOMIA

Q veterinaria

$\%$ OUTRAS 
MOMRELES, A.S.V., CARVALHO, E.N. - Enfermagem, esta desconhecida. Rev. Bras. Enf.; DF, 30 : 185-201, 1977.

TABETA TV - Opinião dos alunos sobre influência e permanência na escolna da profissão

\begin{tabular}{l|c|c}
\hline \multicolumn{1}{c|}{ PRRMANONCIA } & $\begin{array}{c}\text { No DS } \\
\text { ALUNOS }\end{array}$ & $\%$ \\
\hline Não mudaria & 142 & 66,7 \\
$\begin{array}{l}\text { Mudaria após I ten } \\
\text { tativa }\end{array}$ & 20 & 9,4 \\
$\begin{array}{l}\text { Mudaria após ma1s } \\
\text { de } 2 \text { tentativas }\end{array}$ & 47 & 22,1 \\
Som resposta & 4 & 1,8 \\
TOTAL & 213 & 100,0 \\
\hline
\end{tabular}

\begin{tabular}{l|c|c}
\hline \multicolumn{1}{c|}{ INFLUENCIA } & NO DE RES & $\%$ \\
\hline Decisão própria & 190 & 82,2 \\
$\begin{array}{l}\text { Influéncia de paren } \\
\text { tes }\end{array}$ & 1 & 0,5 \\
Orientaçäo vocacio & 49 & 23,0 \\
nal & 5 & 2,3 \\
$\begin{array}{l}\text { Exemplo de tercei- } \\
\text { ros }\end{array}$ & 10 & 4,7 \\
Outras & - & - \\
TOTAL & - & - \\
\hline
\end{tabular}


MERRLES, A.S.V., CARVALHO, E.N. - Enfermagem, esta desconhecida. Rev. Bras. Enf.; DF, 30 : 185-201, 1977.

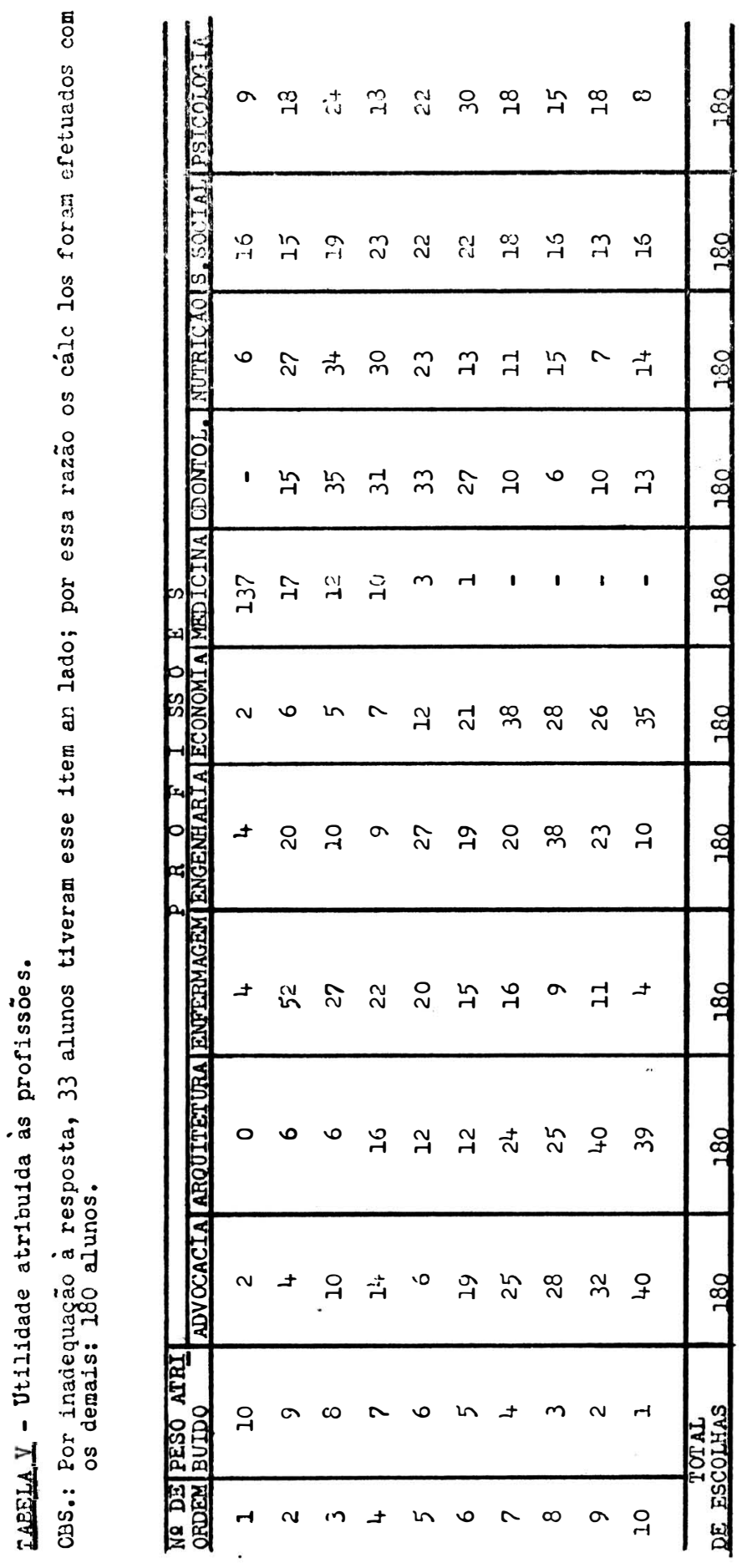


MEIRELES, A.S.V., CARVALHO, E.N. - Enfermagem, esta desconhecida. Rev. Bras. Ene.; DF, 30 : 185-201, 1977.

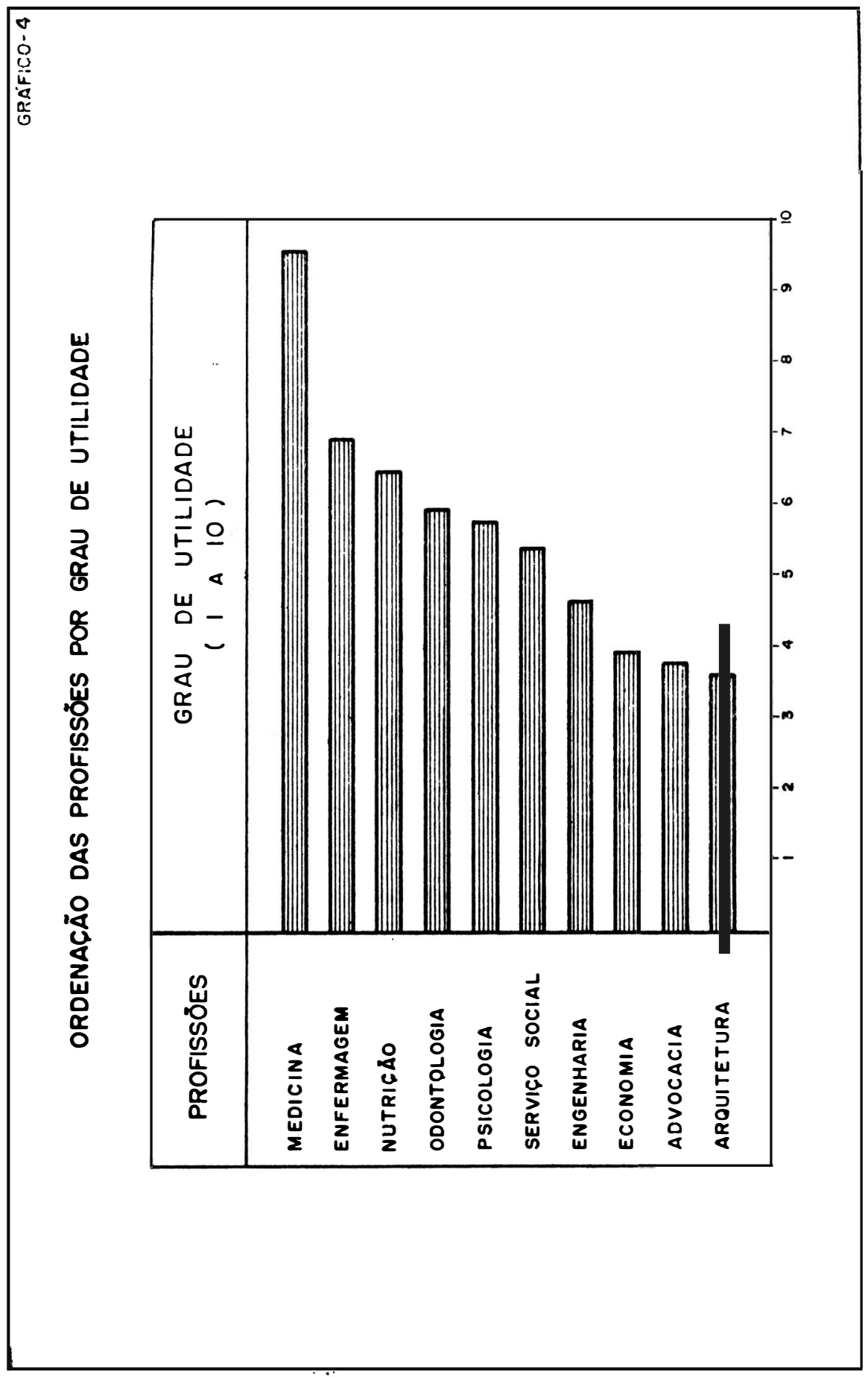


MEIRELES, A.S.V., CARVALHO, E.N. - Enfermagem, esta desconhecida. Rev. Bras. Enf.; DF, 30 : 185-201, 1977.

TABELA VI - Opintão dos alunos sobre a caracterização de prof̣issão, conhecimento da mesma e posicionamento no nível superior.

\begin{tabular}{l|r|r}
\hline \multicolumn{1}{c|}{ CARACTERIZACAO } & $\begin{array}{l}\text { NQ DE } \\
\text { ALUNOS }\end{array}$ & \multicolumn{1}{c}{$\%$} \\
\hline Feminina & 42 & 19,7 \\
Submissa & 7 & 3,3 \\
Desconhecida & 3 & 1,4 \\
Controvertida & 8 & 3,8 \\
Em evolução & 171 & 80,3 \\
\hline
\end{tabular}

\begin{tabular}{l|c|c}
\hline PROEISS ÃO CONHECIDA & NQ DE & \multicolumn{1}{|c|}{ ALUNOS } \\
\hline Sim & 21 & 9,9 \\
Não & 87 & 40,8 \\
Em parte & 105 & 49,3 \\
TOTAL & 213 & 100,0 \\
\hline
\end{tabular}

\begin{tabular}{l|c|c}
\hline ASSISTIU A DIVULGAÇAO & $\begin{array}{c}\text { No DE } \\
\text { ALUNOS }\end{array}$ & $\%$ \\
\hline DE ENFERMAGEM & 61 & 28,6 \\
Sim & 152 & 71,4 \\
Não & 213 & 100,0 \\
TOTAL & & \\
\hline
\end{tabular}

\begin{tabular}{|c|c|c|}
\hline $\begin{array}{l}\text { POSICIONAMENTO EM } \\
\text { NAEL SUPERIOR }\end{array}$ & $\begin{array}{l}\text { No DE } \\
\text { ALUNOS } \\
\end{array}$ & $\%$ \\
\hline Sim & 160 & 75,1 \\
\hline Não & 51 & 23,9 \\
\hline Sem, resposta & 2 & 1,0 \\
\hline TOTAL & 213 & 100,0 \\
\hline
\end{tabular}


MEIRELES, A.S.V., CARVALHO, E.N. - Enfermagem, esta desconhecida. Rev. Bras. Enf.; DF, $30: 185-201,1977$.

TABELA VII - Opintão dos alunos sobre: motivos para abraçar a carrei ra de Enfermagem, funções essenciais e requisitos neces sários do enfermeiro

\begin{tabular}{|c|c|c|}
\hline MOTIVOS & $\begin{array}{l}\text { NO DE } \\
\text { ALUNOS }\end{array}$ & $\%$ \\
\hline Yेouco preparo para concorrer a outra profissão & 19 & 8,9 \\
\hline Pouco tenpo para estudar & 9 & 4,2 \\
\hline Atuar em profissão carente de mão-de-obra & 73 & 34,3 \\
\hline Ajudar outras pessoas & 141 & \\
\hline
\end{tabular}

\begin{tabular}{l|r|c}
\hline \multicolumn{1}{c|}{ FUNCOES ESSENCIAIS } & NQ DE & ALUNOS \\
\hline Orientar a população & 126 & 59,2 \\
Participar nos programas de saúde do país & 116 & 54,5 \\
Fazer pesquisas & 86 & 41,8 \\
Cuidar de pessoas doentes & 140 & 65,7 \\
Chefiar serviços de enfermagem & 37 & 17,4 \\
Aplicar injeções e outros medicamentos & 94 & $44, I$ \\
\hline
\end{tabular}

\begin{tabular}{l|r|c}
\hline \multicolumn{1}{c|}{ REQUISITOS MAIS NECESSARIOS } & NQ DE & ALUNOS \\
\hline Cultura geral & 46 & 21,6 \\
Dedicação e consideração ao ser humano & 200 & 93,9 \\
Conhecimentos científicos & 73 & 43,3 \\
Boa aparència & 21 & 9,8 \\
& & \\
\hline
\end{tabular}

OBS.: En virtude de ser permitido, aos alunos, assinalarem mais de uma alternativa em cada item o total de alunos excede a 213 e o percentual foi calculado para cada alternativa de "per si". 


\section{QUESTIONÁRIO}

Prezado jovem:

profissões.

Estamos necessitando de sua colaboração para uma pesquisa sobre

Sua resposta sincera, neste questionário, será muito valiosa.

Agradecemos desde já sua opinião.

1. Dados pessoais

Instituição em que estuda

Publica ( )

Idade

Particular ( )

Sexo

2. Qual a profissão que você pretende seguir?

Por que?

3. Você mudaria de escolha se não conseguisse passar no vestibular?

( ) após a 1.a tentativa

( ) após mais de duas tentativas

( ) não mudaria

Justifique

4. Na sua opinião, a escolha da profissão depende de:

( ) decisão própria

( ) influência de parentes

( ) orientação vocacional

( ) exemplos de terceiros

( )

(outras)

5. Dentre as profissōes, abaixo citadas, numere em ordem crescente as que você considera mais úteis à sociedade.

Obs.: 0 n.o 1 para a mais útil.

( ) Advocacia

( ) Arquitetura

( ) Enfermagem

() Engenharia 
( ) Economia

( ) Medicina

( ) Odontologia

( ) Nutrição

( ) Psicologia

( ) Serviço Social

6. Quando um jovem abraça a carreira de Enfermagem, você considera que ele:

( ) está pouco preparado para concorrer a vagas em outra profissão?

( ) dispōe de pouco tempo para estudar?

( ) vê oportunidade para atuar numa profissão carente de mão-de-obra?

( ) vê possibilidade de ajudar outras pessoas?

7. Você considera a Enfermagem uma profissão:

( ) feminina

( ) submissa

( ) desconhecida

( ) controvertida

( ) em evolução

8. Você considera a Enfermagem suficientemente conhecida entre os estudantes do $2 .^{\circ}$ grau?
SIM ( )
NAO ( )
EM PARTE ( )

9. Você já assistiu alguma divulgação da Enfermagem?

\section{SIM ( ) NAO ( )}

Se respondeu $S I M$, assinale nas alternativas abaixo:

( ) leituras - revistas, jornais, livros, foḷetos, etc.

( ) filmes - cinema, TV.

( ) conferências $\mathrm{e} / \mathrm{ou}$ palestras

( )

(outras)

10. Em sua opinião, a Enfermagem deve ser uma profissão de nível superior? SIM ( ) NAO ( )

11. Assinale dos itens abaixo, o(os) que você considera funçöes essenciats do enfermeiro:

( ) orientar a população no cuidado da saúde.

( ) participar nos programas de saúde do país.

( ) fazer pesquisas na área da saúde.

( ) cuidar de pessoas doentes.

( ) chefiar serviços de Enfermagem.

() aplicar injeçōes e outros medicamentos.

( ) Outras

12. Na sua opinião, quais dos requisitos abaixo são mais necessários a um enfermeiro?

( ) Cultura geral.

( ) Dedicação e consideração ao ser humano.

( ) Conhecimentos científicos.

( ) Boa aparência. 